\title{
Diverse Profiles of Al-1 Type Quorum Sensing Molecules in Cultivable Bacteria from the Mangrove (Kandelia obovata) Rhizosphere Environment
}

\author{
Zhi P. Ma ${ }^{1,2 t}$, Yong M. Lao ${ }^{1,2 t}$, Hui Jin ${ }^{1,2}$, Guang H. Lin ${ }^{1}$, Zhong H. Cai ${ }^{1,2 *}$ and Jin Zhou ${ }^{1,2 *}$ \\ ${ }^{1}$ The Division of Ocean Science and Technology, Graduate School at Shenzhen, Tsinghua University, Shenzhen, China, \\ 2 Shenzhen Public Platform for Screening and Application of Marine Microbial Resources, Shenzhen, China
}

\section{OPEN ACCESS}

Edited by:

Raquel Peixoto,

Federal University of Rio de Janeiro,

Brazil

Reviewed by:

Adam Schikora,

Julius Kühn-Institut, Germany

Vania Maria M. Melo,

Federal University of Ceará, Brazil

*Correspondence:

Jin Zhou

zhou.jin@sz.tsinghua.edu.cn

Zhong H. Cai

caizh@sz.tsinghua.edu.cn

tThese authors have contributed equally to this work.

Specialty section:

This article was submitted to

Aquatic Microbiology,

a section of the journal

Frontiers in Microbiology

Received: 28 September 2016 Accepted: 22 November 2016

Published: 05 December 2016

Citation:

Ma ZP, Lao YM, Jin H, Lin GH, Cai ZH and Zhou J (2016) Diverse Profiles of Al-1 Type Quorum Sensing Molecules in Cultivable Bacteria from the Mangrove (Kandelia obovata)

Rhizosphere Environment.

Front. Microbiol. 7:1957.

doi: 10.3389/fmicb.2016.01957
Mangrove rhizosphere environment harbors diverse populations of microbes, and some evidence showed that rhizobacteria behavior was regulated by quorum sensing (QS). Investigating the diverse profiles of QS molecules in mangrove ecosystems may shed light on the bacterial roles and lead to a better understanding of the symbiotic interactions between plants and microbes. The aims of the current study focus on identifying Al-1 type QS signals, i.e., acyl homoserine lactones (AHLs), in Kandelia obovata rhizosphere environment. Approximately 1200 rhizobacteria were screened and 184 strains (15.3\%) tested were positive. Subsequent 16s rRNA gene sequencing and dereplication analyses identified 24 species from the positive isolates, which were affiliated to three different phyla, including Proteobacteria, Firmicutes, and Actinobacteria. Thin-layer chromatography separation of extracts revealed diverse AHL profiles and detected at least one active compound in the supernatant of these 24 cultivable AHL-producers. The active extracts from these bacterial isolates were further evaluated by ultra performance liquid chromatography-mass spectrometry, and the carbon side chain length ranged from $\mathrm{C} 4$ to $\mathrm{C} 14$. This is the first report on the diversity of Al-1 type auto-inducers in the mangrove plant $K$. obovata, and it is imperative to expand our knowledge of plant-bacteria interactions with respect to the maintenance of wetland ecosystem health.

Keywords: quorum sensing, acyl homoserine lactone, diverse profiles, rhizobacteria, mangrove plant, plantmicrobes interactions

\section{INTRODUCTION}

Wetland plants contain dense and abundant microbial communities within the thin-layer of root-adherent soil known as the rhizosphere environment (Bulgarelli et al., 2013). Rhizospheric bacteria are living in the direct vicinity of the roots, and root-associated bacteria play important roles in mangrove ecosystem involving nitrogen fixation (Alfaro-Espinoza and Ullrich, 2015), nutrient acquisition (Holguin et al., 2001; Berendsen et al., 2012; Prakash et al., 2015), abiotic stress tolerance (Rout and Southworth, 2013), as well as production of regulators of plant growth and development such as auxins, cytokinins, and gibberellins (Kaai et al., 2008). Additionally, the 
microbial communities associated with root also play an essential role in the matter cycle (for instance phosphorus, organic acids, and siderophores) and maintenance of the health of wetland ecosystem (Gomes et al., 2011; Zeng et al., 2014).

It is noteworthy that the structure and function of mangrove bacterial community determined by the interactions not only between bacterial groups but also between plants and bacteria (Berendsen et al., 2012). Plant-bacteria symbiosis is dependent on molecular and biochemical sensors to be able to dynamically perceive fluxes in their internal and external environments and coordinate the appropriate response at the whole ecosystem level (Scharf et al., 2016). Nevertheless, based on the extremely complex symbiotic relationship between plants and microbes, more work is still needed in order to better understand the important interactions between the inter- or intra-players of ecosystem function, plants and their associated microorganisms. Recent evidence showed that chemical ecology is a robust and efficient methodology to uncover the behavior and ecological functions of microbes (Schwartz et al., 2016).

Quorum sensing (QS) is a common form of chemical signaling receiving increasing attention from marine ecologists recently. QS is the coordinated regulation of gene expression in individual bacterial cells mediated by the population densitydependent release of extracellular signals (autoinducers, AI) to affect many diverse behaviors in a wide range of bacterial species (Banerjee and Ray, 2016). Microbial communities use a variety of molecules, including $N$-acyl-homoserine lactones (AHLs, AI-1), furanosyl borate (AI-2), polypeptides, and diketopiperazines, as autoinducing signals (Boyen et al., 2009; Rajput et al., 2016). Among them, AHLs are arguably the most common and important signaling molecules and regulate various biological functions including biofilm formation, genetic competence, symbiosis, motility, and the production of virulence factors in bacteria (especially in Gram-negative group; Atkinson and Williams, 2009; Hense and Schuster, 2015).

Based on the ecological importance of AHL signal, AHL production and distribution in various niches such as sediment, seaweed, coral, and marine snow have been extensively investigated in the field of marine microbiology (D'AngeloPicard et al., 2005; Scott et al., 2006; DeAngelis et al., 2008; Ransome et al., 2014; Singh and Reddy, 2014; Certner and Vollmer, 2015; Jatt et al., 2015). At the same time, the ecological distribution and potential functions of AHLproducing microbes in plant field have also garnered much attention. AHL signaling has been shown to play a role in the manifestation of the plant-associated phenotypes of numerous autotrophic, pathogenic, and symbiotic bacterial strains (Chong et al., 2012; van Dam and Bouwmeester, 2016; Zhou et al., 2016). A recent study demonstrated that AHL-producing Alphaproteobacteria participated in nitrogen-cycling in legumes plant soil (Venturi and Keel, 2016). Enhanced specific activities of nitrogen-cycling enzymes accompanied by bacterial densitydependent behaviors in the rhizosphere soil suggest that AHL could be a control point in the complex process of rhizosphere nitrogen mineralization (DeAngelis et al., 2008; Lamers et al.,
2012). Furthermore, AHL molecules can affect plant gene expression and physiological features such as growth rate, root development, and resistance to microbial pathogens (Scott et al., 2006; Ma et al., 2014). More recently, the presence of AHL signaling molecules in soil microbes can affect the production of extracellular hydrolytic enzymes, suggesting that AHLs may take part in population communications and co-exist behaviors, especially in plant and other complex environments (Crevelin et al., 2013; Jayaraman et al., 2014; Schikora et al., 2016; Venturi and Keel, 2016).

In wetland biosphere, bacterial communities associated with the rhizosphere of wetland plants seem to be unique because they are shaped by multiple plant and water factors and can form complex biofilms themselves. Furthermore, AHL often occurs in environments that are physically, biologically and chemically heterogeneous. Identification of AHL-producing microbes in rhizospheres of wetland plants could provide important information for understanding bacteria-bacteria and plant-bacteria interactions (Venturi and Keel, 2016). However, to this day, the diversity features of AHL signaling molecules in wetland sediments and their potential effects on plant health are still limited, and only a few studies have focused on mangrove plants (Zeng et al., 2014; Viswanath et al., 2015).

In order to fill this gap, we set out to investigate the diversity of cultivable AHL-producing rhizobacteria associated with the mangrove plant Kandelia obovata by (1) screening for AHL producers using reporter strains; (2) identifying positive bacterial strains by molecular sequencing; (3) profiling the chemical characteristics using thin-layer chromatography (TLC), ultra performance liquid chromatography, and mass spectrometry methods; and (4) drawing the taxonomical position of AHLproducing candidates by evolutionary tree construction. The aims of this work are to dissect the diversity profile of AHLs in the mangrove rhizosphere environment to better understand plant-microbial community associations on the micro-ecological level.

\section{MATERIALS AND METHODS}

\section{Chemicals and Reagents}

Two AHL reporter strains were used in this study: Agrobacterium tumefaciens strains A136 (pCF372-PtraI-lacZ; detection of a broad range of C4-C12 AHLs) and KYC55 (pJZ372traI-lacZ; detection of a broad range of C4-C18 AHLs). The two reporter strains were obtained as gifts from Dr. Zhigang Zhou (Chinese Academy of Agricultural Sciences, Beijing, China). Pseudomonas aeruginosa PAO1 (GDMCC No. 15692) and Escherichia coli DH5 a (GDMCC No. 67878) from Guangdong Microbiology Culture Center of China (GMCC) were used as controls. X-Gal (5-bromo-4-chloro-3-indolyl$\beta$-D-galactopyranoside) and AHL standards were obtained commercially from Sigma-Aldrich (St. Louis, MO, USA). Microbial media and salt solutions were purchased from Guoyao Co., Ltd. (Shanghai, China). Antibiotics, including tetracycline $(4.5 \mu \mathrm{g} / \mathrm{ml})$, spectinomycin $(50 \mu \mathrm{g} / \mathrm{ml})$, kanamycin 
(50 $\mu \mathrm{g} / \mathrm{ml})$, ampicillin $(100 \mu \mathrm{g} / \mathrm{ml})$, and gentamicin $(40 \mu \mathrm{g} / \mathrm{ml})$, were obtained from the National Vaccine and Serum Institute (NVSI, Beijing, China). They were supplemented into the growth medium whenever necessary. Methanol, acetonitrile, and other reagents with purity of $>99.5 \%$ (analytical grade or chromatographical grade) were obtained from Shenggong Co., Ltd. (Shanghai, China).

\section{Sample Collection and Preparation}

Naturally grown $K$. obovata mature fine branch roots with adhering rhizosphere soil were obtained from the Zhanjiang Mangrove National Nature Reserve (110008' E, 20054' N). It is the largest mangrove forest wetland reserve in China (about 20,279 ha), located along coastal areas of the Leizhou Peninsula at the southernmost tip of China between the South China Sea and the Tonkin Gulf, adjacent to Hainan Island. The Reserve is characterized by a subtropical oceanic monsoon climate, and the mean annual temperature is $22.9^{\circ} \mathrm{C}$. The $K$. obovata root samples were collected at a depth of 10-15 cm (upper soil) using a spade and sterile scissors and placed in sterile polythene bags without air in coolers for transport to the laboratory. There are three trial sites to collect the samples, in each site three replicate rhizosphere soil were randomly collected to assemble a composite sample, which was used for bacterial screening. Three grams of root sample were added to $30 \mathrm{ml}$ sterile saline (15 ppt) in a $50 \mathrm{ml}$ sterile centrifuge tube, incubated with shaking for $30 \mathrm{~min}$ and then ultrasonicated for $30 \mathrm{~s}$. Finally, the root was discarded and the soil suspension was separated into two $10 \mathrm{ml}$ sterile tubes. One tube was processed for analysis of the microbial diversity and another tube was used for isolation of the bacterial strains. The environmental parameters temperature, $\mathrm{pH}$, salinity, and conductivity were measured directly in the field, using a multiparameter probe (Multiparameter Display System Model 650, YSI, Yellow Springs, $\mathrm{OH}, \mathrm{USA})$.

\section{Diversity of Rhizobacteria}

DNA was extracted using the PowerSoil kit (MoBio, Carlsbad, CA, USA) according to the manufacturer's instructions. DNA samples were sequenced by Beijing Genomics Institute (BGI, Shenzhen, China) using the Illumina MiSeq platform with the primer set Gray28F-Gray519R as previously described (Lane, 1991). The obtained sequences were processed using Mothur (Schloss et al., 2009) according to the analysis pipeline described on the web site ${ }^{1}$. Sequences were analyzed for features including biodiversity, community, and taxonomy.

\section{Isolation of Bacterial Strains}

The rhizosphere soil suspension was vortexed for $10 \mathrm{~s}$, serially diluted and plated onto $2216 \mathrm{E}$ medium plates containing $1.2 \%$ agar. The formulae of $2216 \mathrm{E}$ medium (per liter) is peptone $(5.0 \mathrm{~g})$, yeast extract $(1.0 \mathrm{~g})$, ferric citrate $(0.1 \mathrm{~g})$, sodium chloride (19.45 g), magnesium chloride (8.8 g), sodium sulfate (3.24 g), calcium chloride $(1.8 \mathrm{~g})$, potassium chloride $(0.55 \mathrm{~g})$, sodium

${ }^{1}$ http://www.mothur.org/wiki/MiSeq_SOP bicarbonate $(0.16 \mathrm{~g})$, potassium bromide $(0.08 \mathrm{~g})$, strontium chloride (34.0 mg), boric acid (22.0 mg), sodium silicate $(4.0 \mathrm{mg})$, sodium fluoride $(2.4 \mathrm{mg})$, ammonium nitrate $(1.6 \mathrm{mg})$, disodium phosphate $(8.0 \mathrm{mg})$, and agar $(12.0 \mathrm{~g})$. The plates were incubated at $28^{\circ} \mathrm{C}$ for $24-48 \mathrm{~h}$. Unique colonies were selected based on color and morphology and transferred into 96-well plates with each well containing $100 \mu \mathrm{l}$ LB (Luria-Bertani) liquid media. The plates were shaken slowly for $12 \mathrm{~h}$. Colonies were mixed with glycerol $(15 \%)$ and stored at $-80^{\circ} \mathrm{C}$ for further analysis.

\section{Screening Test for AHL-Producing Strains \\ Preliminary Screening}

$\mathrm{N}$-acyl-homoserine lactones screen was detected using biosensors according to Chu et al. (2011) methods. Briefly, A136 and KYC55 were grown overnight at $28^{\circ} \mathrm{C}$ in $5 \mathrm{ml}$ of $\mathrm{LB}$ medium. The reactivated rhizosphere isolates was cultured overnight at $28^{\circ} \mathrm{C}$ in 96-well plates. Seventy-five microliter of $5 \times$ diluted A136 overnight culture were added to $75 \mu$ l of samples (activated rhizosphere isolates) in a 96-well plate and incubated at $28^{\circ} \mathrm{C}$ with constant shaking at $150 \mathrm{rpm}$ before X-Gal (final concentration of $40 \mu \mathrm{g} / \mathrm{ml}$ ) was added to each well. Plates were incubated overnight at $28^{\circ} \mathrm{C}$ and the strain with production of blue color after 24-48 $\mathrm{h}$ incubation was recorded as an AHLproducing strain. $P$. aeruginosa PAO1 was used as the positive control and E. coli $\mathrm{DH} 5 \alpha$ as the negative control.

\section{Second Screening}

The potential AHL activity of the isolates was tested by well diffusion agar plate assays as described elsewhere (Zhu et al., 2001; Lv et al., 2016). Briefly, $5 \mathrm{ml}$ overnight reporter strain culture was mixed with $50 \mu \mathrm{l} \mathrm{X}$-Gal in $50 \mathrm{ml} \mathrm{LB}$ media containing $1 \%$ agar when the temperature of the LB was about $45^{\circ} \mathrm{C}$. The mixture was plated and allowed to solidify before sterile filter paper circles $(0.5 \mathrm{~cm}$ diameter $)$ were attached to the LB surface at regular intervals. The putative AHLpositive bacterial strains identified in the preliminary screen were pipetted onto the filter paper. Positive AHL production was recorded as visible blue pigmentation after overnight incubation at $28^{\circ} \mathrm{C}$. AHL production active against A136 was confirmed by streaking the test-isolate on LB agar plates supplemented with $40 \mu \mathrm{g} / \mathrm{ml} \mathrm{X-Gal}$. To detect if any of the isolates produced extracellular factors that could hydrolyze $\mathrm{X}-\mathrm{Gal}$ and thus give a false-positive readout, isolates that produced a blue coloration in the patch test were retested on a plate containing only agar with $\mathrm{X}-\mathrm{Gal}$. Isolates producing blue coloration on these plates were considered false-positive results in the A136 or KYC55 assay and were scored as negative.

\section{Extraction of AHLs}

The AHLs extract was adapted from the procedure of Krick et al. (2007). Each of the isolate cultures was grown $24 \mathrm{~h}$ in $200 \mathrm{ml}$ volume with agitation at $200 \mathrm{rpm}$. The fermentation culture was centrifuged at $12,000 \times g$ for $10 \mathrm{~min}$ and extracted with an equal volume of acidified ethyl acetate $(0.1 \%$ glacial acetic acid). The mixture was then shaken vigorously for $20 \mathrm{~min}$. 
The ethyl acetate phase was removed, and the extraction was repeated. The combined extracts were evaporated in a rotary evaporator at $45^{\circ} \mathrm{C}$. The residue was dried by nitrogen flow, reconstituted in $1 \mathrm{ml}$ acidified ethyl acetate, transferred to HPLC glass vials and re-evaporated. The dry extracts were reconstituted in $100 \mu \mathrm{l}$ acidified ethyl acetate and stored at $-20^{\circ} \mathrm{C}$.

\section{AHL Profiling Using TLC}

The extracted samples together with the standards were profiled using C-18 reverse phase TLC plates $(20 \mathrm{~cm} \times 20 \mathrm{~cm}$ TLC aluminum sheets; RP-18 F254 S, Merck, Germany), and the chromatogram was developed with a methanol/water mixture (60:40) as described by Shaw et al. (1997). The developed active AHL spots were visualized by agar overlay bioassay using the bioreporter strain A136 on TLC plate. For the overlay, approximately $5 \mathrm{ml}$ overnight mid-exponential A136 culture were added to $50 \mathrm{ml} \mathrm{LB}$ media containing $1 \%$ agar and $40 \mu \mathrm{g} / \mathrm{ml} \mathrm{X-Gal.} \mathrm{The} \mathrm{cultures} \mathrm{were} \mathrm{mixed}$ and poured immediately over the developed TLC plates placed in sterile Petri dishes. The plates were incubated overnight and examined for the presence of respective color induction exhibited by the bioreporters. AHL chain lengths were rough calculated by comparing the $R f$ values and the shape of the spots with standard AHLs (N-butanoyl-Lhomoserine lactone (C4-AHL), N-hexanoyl-L-homoserine lactone (C6-AHL), N-octanoyl-DL-homoserine lactone (C8$\mathrm{AHL}$ ), 3-hydroxy-N-homoserine lactone (3-OH-C8-AHL), $\mathrm{N}$-decanoyl-DL-homoserine lactone (C10-AHL), N-dodecanoylDL-homoserine lactone (C12-AHL), and $N$-tetradecanoyl-DLhomoserine lactone (C14-AHL). Standard AHL molecules were obtained from Sigma-Aldrich (St. Louis, MO, USA) and used as controls.

\section{UPLC and MS Analyses of AHLs}

$N$-acyl-homoserine lactones were identified by UPLC and liquid chromatography in tandem with mass spectrometry (LC-MS) detection methods. Samples were kept at $4^{\circ} \mathrm{C}$ until injection, and $10 \mu \mathrm{l}$ of each sample were injected onto a reverse phase C18 core-shell column (Phenomenex Kinetex, Torrance, CA, USA) via a Thermo Electron Surveyor auto-sampler (Thermo Fisher Scientific, Waltham, MA, USA). Separation was obtained using a gradient of $0.1 \%$ acetic acid in water and $0.1 \%$ acetic acid in acetonitrile at a flow rate of $0.3 \mathrm{ml} / \mathrm{min}$. The eluent was introduced into a TSQ Quantum Ultra Triple Stage Quadrupole mass spectrometer (Thermo Scientific) using electrospray ionization, and detection was achieved using multiple reaction monitoring (MRM) in positive ion mode. For identification of AHL molecules, the LC fractions were subjected to electro spray ionization tandem mass spectrometry (ESIMS-MS; Ion Trap MS Esquire 3000 Plus) under positive ion conditions (Ortori et al., 2011). AHL molecules were detected by screening the samples for those precursor ions that gave rise to a fragment ion at $\mathrm{m} / \mathrm{z} 102$. All possible chain lengths ranging from 4 to 20 carbons were included in the method, and the potential to have a hydroxyl or ketone at the three position, with or without a single double bond in the chain, was also taken into account.

\section{Identification of AHL Bacteria by $16 \mathrm{~S}$ rRNA Genotyping}

Genomic DNA from AHL-positive strains was isolated using the UltraClean Microbial DNA Isolation Kit (MoBio Laboratories, Carlsbad, CA, USA). DNA was amplified using the universal primers 8F (5'-AGACTTTGATYMTGGCTCAG-3') and 1512R (5'-GTGAAGCTTACGG(C/T)TAGCTTGTTACGACTT-3')

as previously described (Viswanath et al., 2015). Primers were obtained from the BGI (Shenzhen, China). The reaction mixture included $12.5 \mu$ l Reddy MixPCR master mix containing $1.5 \mathrm{mM}$ $\mathrm{MgCl}_{2}$ and $0.2 \mathrm{mM}$ of each deoxynucleoside triphosphate, $1 \mu \mathrm{l}$ each of the forward and reverse primers, 1-2 $\mu$ l of genomic DNA, and water to bring the total volume to $25 \mu$ l. An initial denaturing hot start of $4 \mathrm{~min}$ at $95^{\circ} \mathrm{C}$ was followed by 30 cycles of $94^{\circ} \mathrm{C}$ for $30 \mathrm{~s}, 55^{\circ} \mathrm{C}$ for $40 \mathrm{~s}$, and $72^{\circ} \mathrm{C}$ for $70 \mathrm{~s}$. The final extension step consisted of $20 \mathrm{~min}$ at $72^{\circ} \mathrm{C}$, concluding the reaction. The PCR products were separated by electrophoresis on a $1.0 \%$ agarose gel and stained with ethidium bromide to confirm that an approximately 1,500 bp product was present. The purified PCR products were then sequenced by BGI (Shenzhen, China).

$16 \mathrm{~S}$ rRNA gene sequences were compared with those in the GenBank database using the basic local alignment search tool BLAST $^{2}$. A $\geq 97 \%$ match of the unknown clone with the GenBank dataset was considered suitable identification at the species level. Similarity of 93-96\% was accepted as genus-level identification (Stackebrandt and Goebel, 1994). The 16S rDNA sequences were aligned using the ClustalW multiple alignment package, ${ }^{3}$ and a consensus region covering all the sequences was selected for further analysis. The aligned sequences were subjected to phylogenetic tree construction using the neighborjoining method provided by the MEGA4 ${ }^{4}$ software package (Kumar et al., 2004). Maximum likelihood bootstrap analyses were carried out with 1,000 replicates.

\section{Statistical Analysis}

The mean and standard deviations of environmental parameters were calculated using the Origin 8.1 software (OriginLab Corp., Northampton, MA, USA).

\section{RESULTS}

\section{Environmental Factors and Relative Diversity of Rhizobacteria}

The sampling habitats were relatively similar in environmental parameters. The temperature, $\mathrm{pH}$, salinity, and conductivity values were $23.4 \pm 0.2^{\circ} \mathrm{C}, 6.36 \pm 0.13,6.90 \pm 0.57 \%$, and $8.65 \pm 1.44 \mathrm{~ms}^{-1}$, respectively.

The relative biodiversity of rhizobacteria was shown in Supplementary Figure S1. A total of 15 phyla were identified from the tested samples, and the top-five phyla (Proteobacteria, Chloroflexi, Bacteroidetes, Planctomycetes,

\footnotetext{
${ }^{2}$ http://www.ncbi.nlm.nih.gov/BLAST

${ }^{3}$ http://www.mbio.ncsu.edu/bioedit/bioedit.html

${ }^{4}$ http://www.megasoftware.net/mega4/mega.html
} 
and Actinobacteria) contributed up to more than $90 \%$ of the total quality reads (Supplementary Figure S1A). Among the Proteobacteria, Gamma-proteobacteria, Delta-proteobacteria, and Alpha-proteobacteria were the most abundant classes, which occupied 64.4, 25.8, and 7.7\% percentage (Supplementary Figure S1B). The Candidate division WS3, Gemmatimonadetes, Actinobacteria, Deferribacteres, and Spirochaetae as the minorities and comprised $2.0,1.4,0.9,0.7$, and $0.5 \%$ of the total population, respectively. The unidentified species is about $2.5 \%$ (Supplementary Figure S1A). When sequences were assigned to the taxonomic rank of "order," 10 taxonomic groups were found to make up $88.9 \%$ of the total quality reads. Vibrionales (43.8\%) and Desulfobacterales (15.7\%) were the two most abundant, followed by Anaerolineales (5.5\%), Alteromonadales (5.5\%), Xanthomonadales (4.5\%), Myxococcales (3.6\%), Rhodospirillales (3.5\%), Chromatiales (3.1\%), Cytophagales (1.8\%), and Oceanospirillales (1.5\%). The less abundant taxa (near 1\%) were Rhizobiales (1.26\%), Desulfuromonadales (1.07\%), Deferribacterales (1.01\%), Rhodobacterales (0.98\%), and Desulfarculales (0.79\%; Supplementary Figure S1C).

\section{Screening for AHL Producers}

A total of 1200 cultivable strains were isolated from rhizosphere soil and screened for AHL activity. Of these isolates, 300 were identified as AHL-producing candidates active with at least one of the two reporter strains (A136 or KYC55) in the preliminary screening. After verification by second screening and removal of false-positives (the rate was about 20\%), 184 bacterial strains gave rise to a positive signal as blue color zones with both reporter strains (A136 and KYC55) were observed. The activity of positive isolates was recorded as either strong $(++)$ or weak $(+)$ based on the color intensity produced by the reporter strains. The data obtained are summarized in Table 1 (part A). In total, AHLproducing bacteria represented $15.33 \%$ (184/1200) of all cultured bacteria isolated from $K$. obovata rhizosphere soils.

\section{Identification of AHL-Producing Bacterial Strains by $16 S$ rRNA Sequencing}

The 16S rRNA gene sequences of these 184 bacterial isolates were aligned to the NCBI database using BLAST. BLAST results showed that 82 of the total belonged to the class Gammaproteobacteria, 45 to the class Alpha-proteobacteria, 36 to the phylum Firmicutes, and 17 to the phylum Actinobacteria. After dereplication analyses, 24 AHL-producing rhizobacterial representatives were chosen from the candidates for taxonomical identification and AHL profiling studies. Most of the representative isolates shared $99 \%$ sequence similarity and five of them had a $100 \%$ sequence similarity with their respective

TABLE 1 | $\mathbf{N}$-acyl-homoserine lactone (AHL) profiling of 24 representative rhizobacteria isolated from the mangrove rhizosphere environment.

\begin{tabular}{|c|c|c|c|c|c|c|}
\hline \multicolumn{3}{|c|}{ Part A } & \multicolumn{4}{|c|}{ Part B } \\
\hline Strain No. & A136 & KYC55 & OTU No. & Closest cultivated bacteria & ID at 16S-rRNA gene cocus & Potential AHL compounds* \\
\hline Strain 1 & ++ & ++ & OTU1 & Enterobacter sp. & $99 \%$ & $\mathrm{C} 12-, \mathrm{C} 8-\mathrm{OH}, \mathrm{C} 6-$ \\
\hline Strain 2 & ++ & ++ & OTU2 & Pasteurella pneumotropica & $100 \%$ & C12-, C10-, C8-OH, C6- \\
\hline Strain 3 & ++ & ++ & OTU3 & Photobacterium rosenbergii & $99 \%$ & C12-, C8-, C8-OH \\
\hline Strain 4 & ++ & ++ & OTU5 & Vibrio fluvialis & $99 \%$ & $\mathrm{C} 8-\mathrm{OH}$ \\
\hline Strain 5 & ++ & ++ & OTU6 & Gallaecimonas sp. & $99 \%$ & C10- \\
\hline Strain 6 & + & ++ & OTU8 & Staphylococcus xylosus & $99 \%$ & C10- \\
\hline Strain 7 & + & + & OTU9 & Vibrio sinaloensis & $99 \%$ & $\mathrm{C} 8-\mathrm{OH}$ \\
\hline Strain 8 & ++ & ++ & OTU10 & Brachybacterium paraconglomeratum & $99 \%$ & $\mathrm{C} 14-, \mathrm{C} 12-, \mathrm{C} 8-\mathrm{OH}$ \\
\hline Strain 9 & + & + & OTU11 & Bacillus aerophilus & $99 \%$ & $\mathrm{C} 12-, \mathrm{C} 10-, \mathrm{C} 8-\mathrm{OH}$ \\
\hline Strain 10 & ++ & ++ & OTU12 & Vibrio communis & $100 \%$ & C12-, C10-, C8-OH \\
\hline Strain 11 & + & ++ & OTU13 & Staphylococcus saprophyticus & $100 \%$ & $\mathrm{C} 14, \mathrm{C} 12-, \mathrm{C} 8-\mathrm{OH}$ \\
\hline Strain 12 & + & - & OTU14 & Photobacterium sp. & $99 \%$ & C12- \\
\hline Strain 13 & + & + & OTU15 & Bacillus sp1. & $99 \%$ & C14-, C12- \\
\hline Strain 14 & ++ & + & OTU17 & Bacillus aquimaris & $99 \%$ & C8- \\
\hline Strain 15 & ++ & ++ & OTU18 & Vibrio sp. & $99 \%$ & $\mathrm{C} 14-, \mathrm{C} 12-, \mathrm{C} 8-\mathrm{OH}$ \\
\hline Strain 16 & + & + & OTU19 & Bacillus cereus & $99 \%$ & C8- \\
\hline Strain 17 & + & + & OTU20 & Paenibacillus sp. & $100 \%$ & C12-, C8- \\
\hline Strain 18 & ++ & ++ & OTU21 & Paracoccus sp. & $100 \%$ & C12-, C10-, C8-, C6- \\
\hline Strain 19 & ++ & ++ & OTU22 & Psychrobacter sp. & $99 \%$ & C14-, C12-, C8- \\
\hline Strain 20 & + & + & OTU23 & Bacillus sp2. & $99 \%$ & C8- \\
\hline Strain 21 & ++ & - & OTU24 & Alteromonas sp. & $99 \%$ & C10- \\
\hline Strain 22 & ++ & ++ & OTU26 & Acinetobacter sp. & $99 \%$ & C12- \\
\hline Strain 23 & ++ & ++ & OTU27 & Pseudomonas chlororaphis & $99 \%$ & C14-, C12-, C10- \\
\hline Strain 24 & ++ & ++ & OTU28 & Pseudomonas aeruginosa & $98 \%$ & $\mathrm{C} 14-, \mathrm{C} 10-, \mathrm{C} 8-\mathrm{OH}$ \\
\hline
\end{tabular}

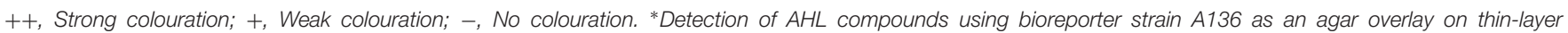

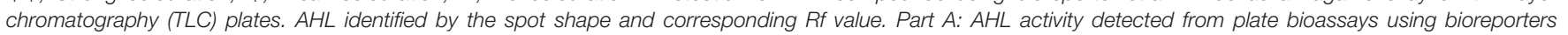
(A136 and KYC55). Part B: Identification and compounds information of AHL-producers. 
reference strains (Table 1, part B). These 24 bacterial strains represented four different bacterial groups, 13 belonging to Gamma-proteobacteria, 9 to Firmicutes, 1 to Alphaproteobacteria, and 1 to Actinobacteria. The bacterial sequences have been submitted to GenBank Database and the accession number is KX941451-KX941474.

A phylogenetic tree based on the 16S rRNA gene sequences was constructed by neighbor joining clustering for the 24 AHLpositive bacterial strains. The AHL producers were classified into four different bacterial clusters, namely Gamma-proteobacteria, Actinobacteria, Alpha-Proteobacteria, and Firmicutes (Figure 1). In the Gamma-proteobacteria family, most of the positive strains were related to the genus Vibrio sp., Enterobacter sp., Alteromonas sp., Photobacterium sp., and Pseudomonas sp. Six AHL-producing members of the Firmicutes group were closely related to the genus Bacillus sp., two to Staphylococcus sp., and only one to the genus Paenibacillus sp. One strain (OTU21), for which AHL activity was only detected by the bioluminescent reporter strain A136, was assigned to the Paracoccus genus of Alpha-proteobacteria. 16S rRNA gene sequence analysis indicated that OTU10 shared the greatest similarity to the Brachybacterium sp. (99\% similarity), forming a cluster in Actinobacteria, which was closely related to B. paraconglomeratum. Remarkably, this strain belongs to a genus that has never been reported to synthesize AHLs.

\section{Profiling of AHL Molecules}

Reverse phase TLC was utilized to determine the signal molecule profiles of the 24 positive strains. A diverse range of $\mathrm{AHL}$ profiles was observed among the mangrove rhizobacteria. Most of the isolates produced more than one active compound, which included both 3-unsubstituted acyl-AHLs and 3-hydroxysubstituted acyl-AHLs (Figure 2). Among the AHL substances, the dominant signals belonged to mid length compounds ranging from C8- to C12-. The most common AHL variant produced by the 24 isolates was $\mathrm{C} 12-$, produced by $17(70.8 \%)$ of the strains in liquid culture, followed by $\mathrm{C} 8$ - or $\mathrm{OH}-\mathrm{C} 8$-, detected in $12(50.0 \%)$ of the strains. A broad range of AHL molecules, including short- and long-chains with different substituted side chains (C6-C12 or C8-C14), was detected in some strains. For example, the Bacillus aerophilus (OTU11) and Vibrio communis (OTU12) produced triple AHL profiles that had three circular spots with $R f$ values of $0.52,0.33$, and 0.18 , representing C8$\mathrm{OH}, \mathrm{C10}-$, and C12-AHL, respectively. In addition, Bacillus sp3. (OTU15) and Pasteurella pneumotropica (OTU2) produced a double and a quadruple spot in the TLC plate, respectively (Table 1, Part B).

\section{UPLC and LC-MS Analysis of AHLs}

$N$-acyl-homoserine lactone-positive strain extracts on the TLC plate were spiked and further analyzed by UPLC. Peaks of samples and AHLs standards were combined at a retention time of $10.0 \mathrm{~min}$. A calibration curve was prepared with standard AHLs and used to estimate the AHL amount in the extracts at various time points. The controls were mixtures of six AHL standards (C6, C8, C8-OH, C10, C12, and C14) with their retention times. For example, for samples 15 (OTU18) and 17 (OTU20), peaks 7 and 10 are likely C12-AHL, peaks 8 and 11 are C8-AHL, and peak 9 is C14-AHL (Figure 3; Table 1, part B).

Liquid chromatography in tandem with mass spectrometry (LC-MS) of AHLs contains a molecular ion $[\mathrm{M}+\mathrm{H}]^{+}$or $[\mathrm{M}+\mathrm{Na}]^{+}$peak and a characteristic lactone fragment peak at $\mathrm{m} / \mathrm{z}$ of 102 . Based on these two analyses (TLC and LC-MS), the corresponding AHL substances of these AHL molecules were identified. For example, LC-MS data for the OTU2 extract show the presence of a characteristic lactone fragment at $\mathrm{m} / \mathrm{z}$ of 102 and the molecular ion peak at $\mathrm{m} / \mathrm{z}$ of 200 or 222 $\left[\mathrm{Na}^{+}\right]$, suggesting the AHL to be C6-AHL (spot 1; Figure 4A). Accordingly, spot 2 (B), spot 3 (C), and spot 4 (D) are C6-OAHL, C8-AHL, and C10- or C12-AHL, respectively. Figure 4 shows the LC-MS spectra acquired from chromatographic runs of extracts with chromatographic peaks that further confirm the patterns observed on the TLC plates. The LC-MS analysis further revealed that the isolates produced AHLs of varying acyl chain lengths ranging from 6 to 14 carbons. Some signalproducing isolate synthesized more than one type of AHL, and multiple genera/species could produce the same AHL. The dominant signal detected in the root community was from medium AHLs.

\section{DISCUSSION}

\section{Overview of Bacterial Diversity}

The dominant native mangrove species in Leizhou Reserve are K. obovata, Aegiceras corniculatum, and Avicennia marina. In the present study, we focused on $K$. obovata and found that prokaryotic communities in mangrove roots were dominated by Proteobacteria, Chloroflexi, Bacteroidetes (previously Cytophaga-Flexibacter-Bacteroides), Planctomycetes, and Actinobacteria (Supplementary Figure S1A). The observation was consistent with previous reports (Andreote et al., 2012; Hong et al., 2015; Zhang et al., 2015). Among the Proteobacteria, Gamma-proteobacteria, Delta-proteobacteria, and Alphaproteobacteria were the three most abundant classes in our sampling sites (Supplementary Figure S1B), in agreement with previous findings in Aegiceras corniculatum, Avicennia marina, and Sonneratia caseolaris (Yang et al., 2014; Alzubaidy et al., 2016; Chen et al., 2016). These results suggest that Alpha-, Gamma-, and Epsilon-proteobacteria are prevalent in mangrove plants. Beta-, Zeta- and Epsilon-proteobacteria comprise only $2.02 \%$ of the total quality reads, which is lower than Liang et al. (2007) reported result (16\%). Biogeography (distinct soil depths and locations) may be a major determinant factor that influences bacterial structure. In addition, anthropogenic interference may contribute to this difference, because various degrees of human activities (urbanization, pollution, and aquaculture) have different effects on environmental competitiveness and co-shaping the microbial communities (Marcial et al., 2008; Basak et al., 2015; Chakraborty et al., 2015).

At order level, Vibrionales (belongs to Gammaproteobacteria) was the most predominant group and 


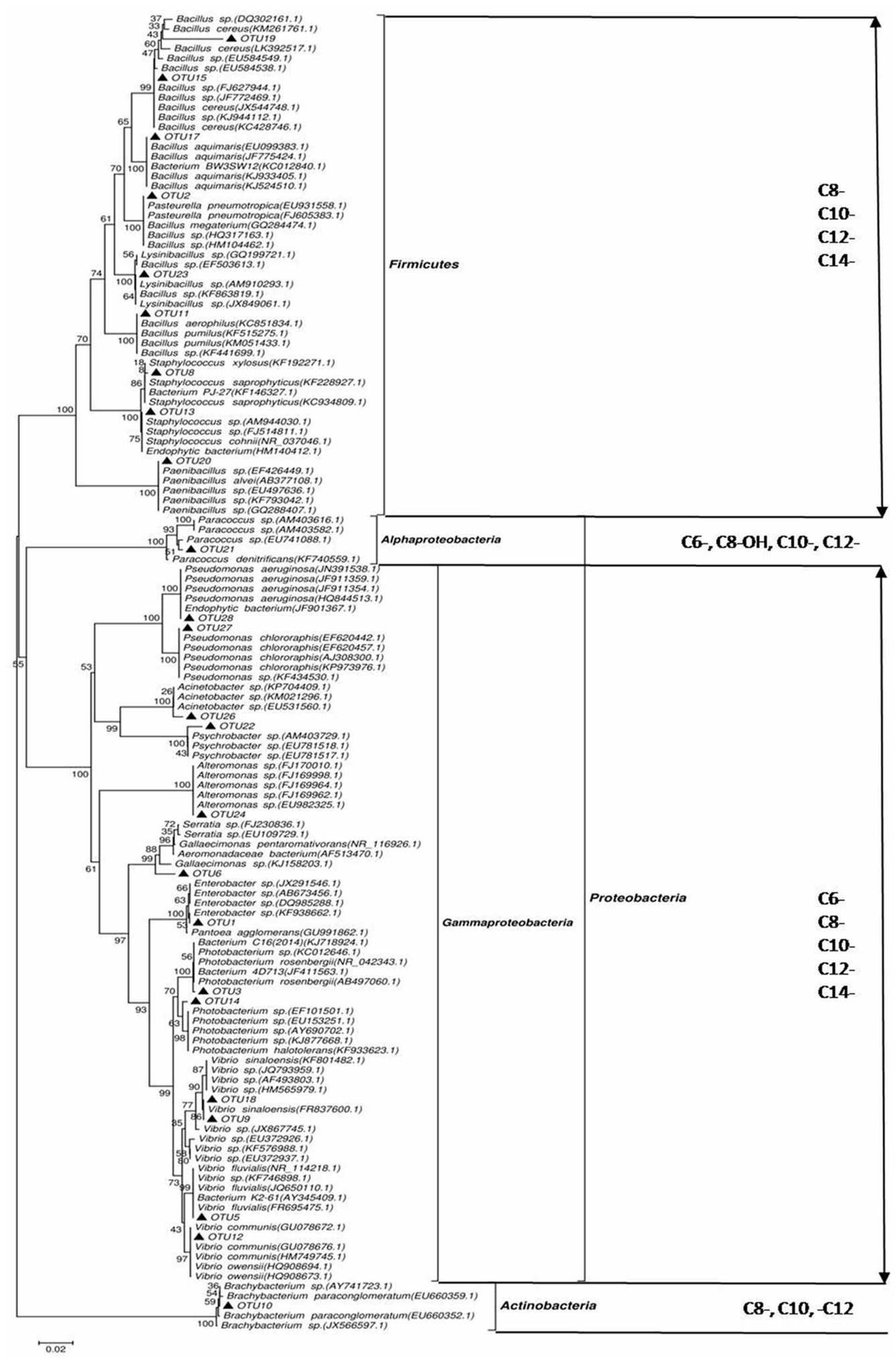

FIGURE 1 | Phylogenetic tree of $\mathbf{N}$-acyl-homoserine lactone (AHL)-producing rhizobacteria based on neighbor joining clustering and species identification by $16 \mathrm{~S}$ rRNA gene sequence alignment to the NCBI GenBank database. Phylum taxa appear on the right, with the external distribution made by class and the internal distribution made by genus. $\mathbf{\Lambda}$, isolates that induced AHL activity detected by the A136 indicator strain. Bootstrap probabilities are indicated at branch nodes (values under 50\% were excluded). The bar represents three substitutions per 100 nucleotide positions. GenBank accession numbers deposited in the NCBI database are given for partial 16S rRNA sequences of all isolates. 


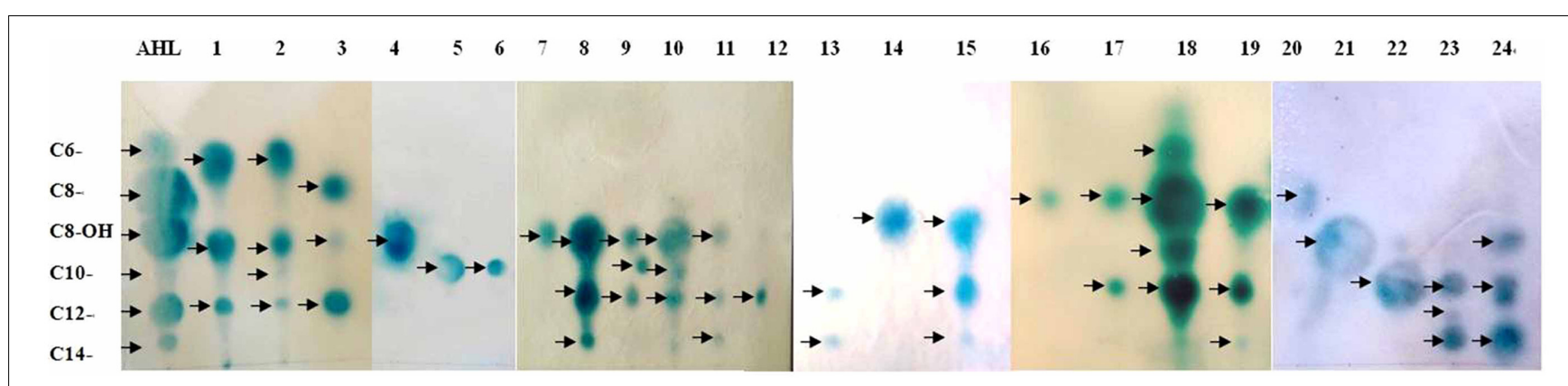

FIGURE 2 | Analysis of AHLs from supernatant extracts with the sensor strain. AHLs extracted from cell-free culture supernatants were separated by thin-layer chromatography (TLC) and detected using an overlay of agar seeded with A. tumefaciens 136. Line AHL are the QS standards (arrows point to C6-, C8-, $\mathrm{OH}-\mathrm{C} 8-, \mathrm{C10}-$, C12-, and C14-AHL, respectively). Lines 1-24 represent the sample extracts. The strain names were: Enterobacter sp., Pasteurella pneumotropica, Photobacterium rosenbergii, Vibrio fluvialis, Gallaecimonas sp., Staphylococcus xylosus, Vibrio sinaloensis, Brachybacterium paraconglomeratum, Bacillus aerophilus, Vibrio communis, Staphylococcus saprophyticus, Photobacterium sp., Bacillus sp1., Bacillus aquimaris, Vibrio sp., Bacillus cereus, Paenibacillus sp., Paracoccus sp., Psychrobacter sp., Bacillus sp2., Alteromonas sp., Acinetobacter sp., Pseudomonas chlororaphis, and Pseudomonas aeruginosa.

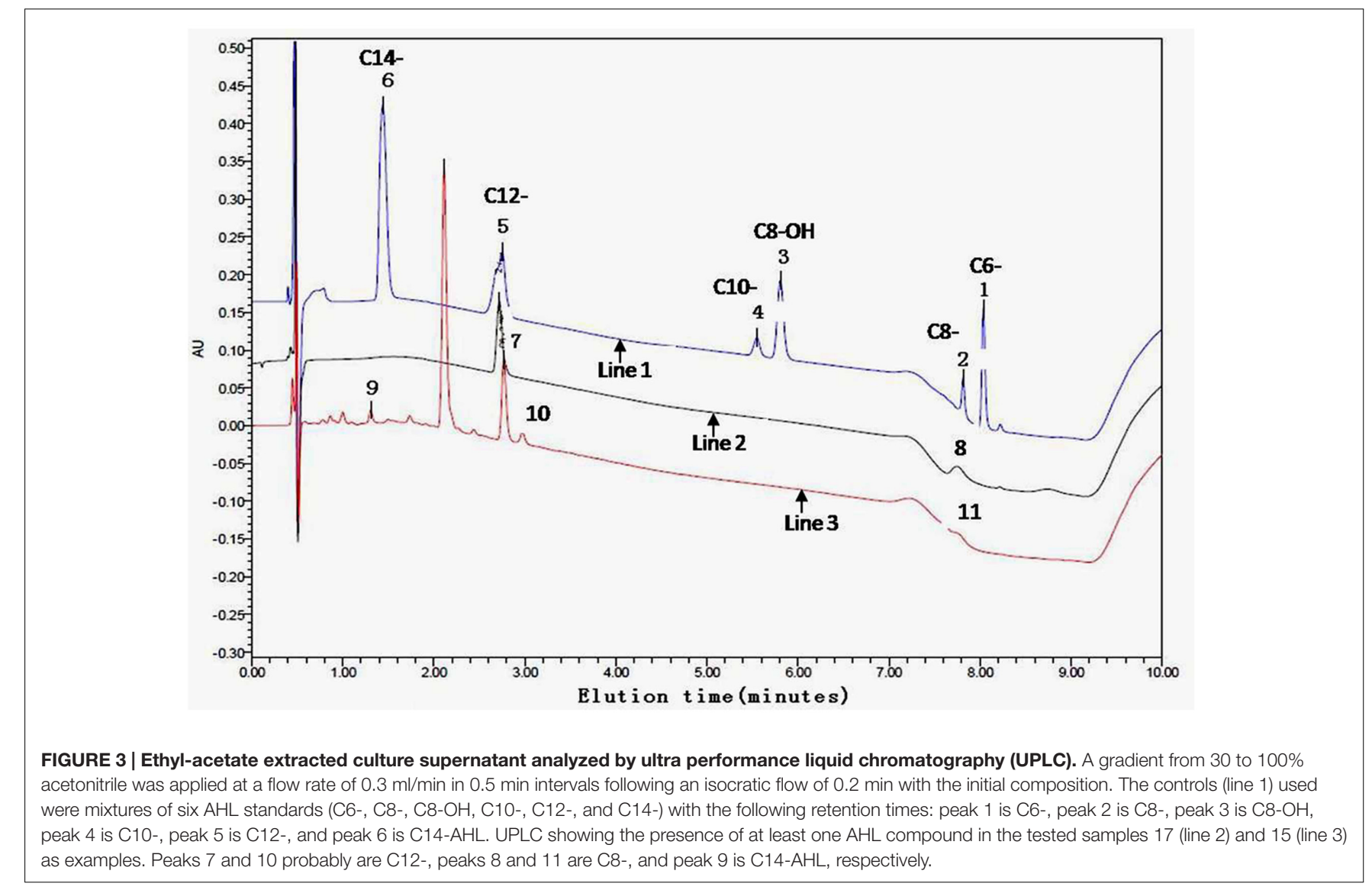

approximately $43.8 \%$ of the OTU sequences were classified in it (Supplementary Figure S1C). The abundance of Vibrionales was much higher in $K$. obovata rhizosphere samples than bulk sediment samples (Yin et al., 2016). The possibility of this distribution pattern of Vibrionales may be attributed to the contribution of root influence. Around the mangrove habitat, root secrete can attract some heterotrophic bacteria and most of them were Vibrionales, Actinomycetales, and
Bacillales (Dias et al., 2009). Desulfobacterales (belongs to Deltaproteobacteria) sequences represent the second largest fraction (15.7\%) of total quality reads at class level, and the abundance of Desulfobacterales is higher compared with that in published literature (Zhang et al., 2016). The Desulfovibrionales has been reported to be able to adapt to or tolerate to environmental stresses, such as low salinity or low sulfate supply (Kuever et al., 2005; Leloup et al., 2006), heavy metals contamination (Cabrera 


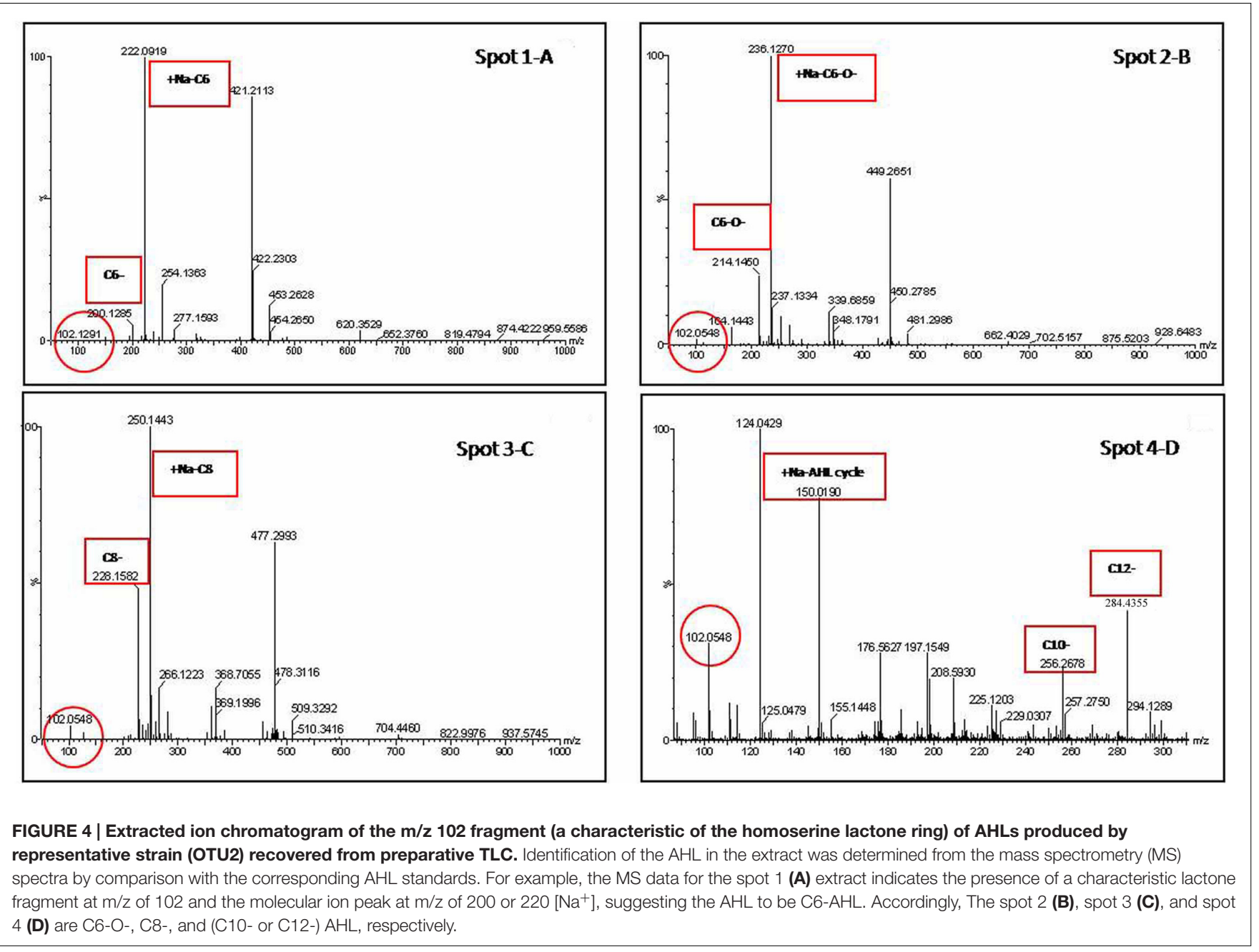

et al., 2006), and anthropogenic activities (Miralles et al., 2007). The presence of such organisms and the shifts observed in these groups are indications that the effects of environmental conditions on mangrove functioning might exert selection pressure on the sulfate- and sulfite-reducing process. In addition, Desulfovibrionales has a more efficient nutrient uptake and reduced energy utilization in oligotrophic environment (VaronLopez et al., 2014), partly explaining their distinct distribution patterns. It is worthwhile to note that some fluctuates appeared in non-abundant species (Anaerolineales, Alteromonadales, Xanthomonadales, Myxococcales, Rhodospirillales, and Chromatiales), hinting the possibility of terrigenous influence in the community variation.

\section{Relative Occurrence of AHL-Producers in the Rhizosphere Environment}

This work found the presence of AHL-producers among the K. obovata rhizobacteria, comprising $15.33 \%$ of a total of 1200 cultivable bacterial strains. In this study, the $\mathrm{pH}$ value in rhizosphere environment ranged from 6.23 to 6.49 , making the mangrove soils suitable environment for AHL substances or their producers. Furthermore, the high percentage of AHL-producing strains isolated in the present study could indicate that AHLs are strategically used in the rhizosphere niche to achieve competitive advantages, at least in the fluctuating mangrove habitats exposed to tidal cycles (Krumme et al., 2012). More detailed studies on the presence of AHL activity in cultivable bacteria in mangrove plants should be carried out and would likely add valuable information to the elucidation of the ecological importance of AHL-mediated micro-environmental processes in the wetland ecosystem (Romero et al., 2011).

Among the 24 AHL-producing rhizobacterial representatives, $16 \mathrm{~S}$ rRNA gene sequences exhibited greater than 98\% similarity to known species belonging to the genera Bacillus, Photobacterium, Gallaecimonas, Vibrio, Staphylococcus, Alteromonas, Paracoccus, Brachybacterium, Pseudomonas, Acinetobacter, Enterobacter, and Psychrobacter (Table 1). The Alpha- and Gamma-proteobacteria represented approximately $60 \%$ of these AHL-producing bacteria. The fact that most of these AHL-producing bacteria are Proteobacteria is in agreement with the up-to-date reports that AHL synthesis has only been found in the members of these three phylogenetic groups (alpha-, beta-, and gamma-) so far (Gray and Garey, 2001; Manefield 
and Turner, 2002). The remaining strains belong to Firmicutes (Paenibacillus sp.) and Actinomyces (Brachybacterium sp.). Some AHL producers isolated in this study belong to known AHLproducing genera but other strains were detected for the first time, including Brachybacterium paraconglomeratum (belongs to the Dermabacteraceae family) and Acinetobacter sp., which implied mangrove root habitat as a reservoir for AHL screen to be explored. Interestingly, we identified three Gram-positive bacteria (Staphylococcus sp., Bacillus sp., and Brachybacterium sp.) that could produce AHLs. Since presently known AHL producers are Gram-negative bacteria, we speculated that genetic events (gene flow or horizontal gene transfer) from certain Gram-negative bacterium/bacteria might occur to confer the AHL productivity to Gram-positive individual. Deeper sequence analysis of this strain will allow these hypotheses to be assessed and an ecological interpretation of this functional versatility to be proposed (Biswa and Doble, 2013).

It is worth noting that compared to the composition of total microbial structures in rhizobacteria, five phyla (Proteobacteria, Chloroflexi, Bacteroidetes, Planctomycetes, and Actinobacteria) dominated the strains, comprising more than $90 \%$ percent of the total OTUs (Supplementary Figure S1A). In agreement with this, the cultivated root-associated strains producing AHLs seem to be more frequently clustered with these bacteria which are commonly found in the rhizosphere holobiont. This observation suggests that AHL producers mainly come from the predominate taxa.

\section{The Diversity and Characterization of AHLs}

Thin-layer chromatography coupled with AHL bioreporters gave a rapid and directly visible system for the detection of AHL molecules. UPLC and LC-MS further confirmed the inducing signal to come from AHL substances (Figures 3 and 4 ). The TLC plate showed more than one AHL molecule in each positive isolate and most frequently identified medium- or long-chain AHLs (such as C8-, C10-, and C12-; Figure 2). The broad AHL spectrum suggests that the root microbial community has the capacity to synthesize multiple signals. This observation also corresponds with the profile of AHLs identified in the floccular sludge community (Tan et al., 2014). In addition, our results are consistent with a previous report that AHL-producing bacteria often produce long-chain rather than short-chain AHLs (Wagner-Dobler et al., 2005). This could be because shortchain AHLs are known to degrade more rapidly in saltwater environments (Hmelo and Van Mooy, 2009). Furthermore, based on the $\mathrm{pH}$ sensitivity of AHL molecules, low or high soil $\mathrm{pH}$ may be negative selection factors for short-chain AHLproducers. This suggests a dominance of longer-chain AHLs associated with the mangrove root species, where moderate acid $\mathrm{pH}$ predominates. In addition to the above-mentioned points, secreting medium- and long-chain AHL molecules could be an intelligent behavior of bacteria balancing the energy expended on self-preservation and ecological function (Winans, 2006; Jia et al., 2016). This hypothesis still needs to be further confirmed in future studies.
From the TLC results, we saw that isolates varied in the relatively quantity of AHL production (Table 1, part B). It has been suggested that there could be more than one AHLregulatory system, and that more than one signal molecule could be produced by AHL synthases (Viswanath et al., 2015). The high heterogeneity in AHL production is in agreement with the high genetic diversity bacterial species. Though some bacterial isolates representing different genera produce a similar group of AHL molecules; for example, the major products among the representative Proteobacteria as well as Firmicutes are mediumchain AHLs (C8-C12), the roles of these similar AHLs in the phenotypic regulation may differ between different strains. This might be due to the procurement of homologous AHL genes by means of horizontal gene flow. Thus, the production of similar types of AHL molecules in different genera might help interspecies communication in the natural environment where mixed communities are often present (Viswanath et al., 2015).

In previous studies, researchers found that AHL profiles were not strictly conserved at the genus or species levels (Zimmer et al., 2014; Rajput et al., 2016). Hence, some phylogenetically distant species exhibited similar AHL profiles. Several studies can provide plausible explanations for these complex patterns of AHL production. At the molecular level, the amino acid sequences of AHL synthases sometimes are more dissimilar within one species than between distinct species (Gray and Garey, 2001). At the ecological and evolutionary level, multiple AHL synthase homologs or multiple luxI/luxR determinants in a bacterium could be acquired independently (D'Angelo-Picard et al., 2005). In addition, such heterogeneity within AHL profiles may result from a selective pressure that favors distinct molecular languages at the subspecies level, especially when related organisms share common ecological niches such as the rhizosphere (Steidle et al., 2001).

It is worth noting that we identified some AHL-producing isolates (for example, Vibrio sp. and Aeromonas sp.) that also have AHL-degrading genes or regulators using the SigMol tool (Rajput et al., 2016). The coupling of AHL synthesis and degradation in the same bacterium has previously been noted for Agrobacterium tumefaciens, which produces and degrades 3-oxo-C8-AHL via a lactonase encoded by AttM that is activated by starvation signals and stress alarmone (p)ppGpp (Zhang et al., 2004). Haudecoeur and Faure (2010) further pointed out that A. tumefaciens C58 exhibits a fine control of biosynthesis and biodegradation of O-C8-AHL by lactonases AttM and AiiB. Similarly, a marine Shewanella strain that produces AHLs in the late exponential phase degrades its long-chain AHLs via both lactonase and acylase/amidase activities (Tait et al., 2009). Indeed, organisms known to be AHL producers or quenchers, such as members of Proteobacteria and Bacteroidetes phyla, have recently been expanded to also include Cyanobacteria, Acidobacteria, and Archaea from a diverse range of environments (Chan et al., 2011; Tan et al., 2015). So why do some strains of the same species act as AHL producers or degraders in different specified circumstances? In the rhizosphere habitat, extremely diverse microbial species co-exist, and the co-occurrence of AHL and anti-AHL activities is likely common (D'Angelo-Picard et al., 
2005). A preliminary molecular analysis in our group suggests that multiple AHL-producing and AHL-quenching genes are present in the same marine bacterium from draft genome sequences (data not shown), supporting the co-occurrence of AHL and anti-AHL activities in the bioreactor. As for the role of these bifunctional bacteria, we speculate that they modulate signaling at the community level and could potentially be used as bio-controllers targeting AHL-regulated functions, especially in complex environments (D’Angelo-Picard et al., 2005). For instance, as suggested earlier, the lack of short-chain AHLs in the root may not be due to the absence of producer strains but more likely a consequence of specific AHL-degrading activity by the community.

\section{The Connection between the Root and AHLs or AHLs-Producers}

Quorum sensing signals play an important role in the ecological interactions between bacteria and their eukaryotic hosts. In terrestrial plants, QS can control the virulence of pathogens to tobacco (Chevrot et al., 2006; Lang et al., 2016), and quorum-quenching bacteria capable of promote potato (Solanum tuberosum) growth (Cirou et al., 2007). In aquatic environment, many work have also demonstrated that AHLs can regulate the plant hosts' ecological behaviors, including red algae biofouling (Manefield et al., 1999), green seaweed attachment (Joint et al., 2007), sponge release (Taylor et al., 2004), phycosphere carbon cycle (Huang et al., 2016), and marine snow alkaline phosphatase biosynthesis (Jatt et al., 2015). Similar phenomena were observed in the mangrove habitat; a conceptual model suggested that bacterial density-dependent behaviors might play a role in regulating mangrove soil nitrogencycling (DeAngelis et al., 2008). Density-dependent QS provides an interesting potential checkpoint for enzymes mediating organic nitrogen depolymerization and rhizosphere nitrogen mineralization (DeAngelis et al., 2008). These findings indicate that QS is an essential ecological signal modulator between plant and microbes.

This study has initiated steps toward understanding the role of AHL-producing bacteria associated with mangroves. Mangrove soil functions are closely related to bacterial activities, some plantgrowth-promoting or biocontrol bacteria are key regulators for host healthy. Previously, Joseph and Phillips (2003) deemed it is conceivable that bacterial AHLs may represent a plant-microbe interaction in which both plant and root-associated bacteria benefit from the production of QS signals in the rhizosphere. It is possible to affect soil function by controlling bacterial activity in the soil via QS (Huang et al., 2013; Zeng et al., 2014). The study of the distribution and diversity of AHLproducers greatly increases our knowledge about potential cellcell communications in natural niches and provides valuable information for the in situ control of bacterial activities. In this current work, 24 AHL-producing genera, such as Alteromonas, Vibrio, and Pseudomonas were identified in wetland samples using culture-dependent methods. Functionally, these putative AHL-producers could be classified into four groups according to their closest matches to indicate their possible relationships with the host plant: plant growth promotion, pathogenesis, nitrogenfixing, and bioremediation (Parte et al., 2010). Alteromonas sp. and Photobacterium sp. were the predominant cultivable AHL-producers in the rhizosphere of wetland plants. Species from these two genera, such as $A$. veronii and $P$. rosenbergii, may act as beneficial rhizobacteria (plant growth promotion rhizobacteria, PGPR) to promote growth of plant (Ortiz-Castro et al., 2009). PGPR are able to stimulate plant growth by direct or indirect mechanisms, like production of phytohormones, mineralization of organic matter, and competing with pathogens (Ortiz-Castro et al., 2009). Some Pseudomonas and Vibrio species were considered to be potential pathogen to wetland plants (Pollumaa et al., 2012). Previously, QS has been shown to control Ti plasmid transfer in tumor-forming Agrobacterium spp. and virulence factor production in soft-rotting $P$. carotovorum (Pollumaa et al., 2012; Lang et al., 2016). Communication via diffusible signaling molecules between plants and bacteria has been proposed to be one of the important regulators in symbiotic behaviors (Scott et al., 2006).

In order to address the complete picture of AHL-producers and their ecological functions in the mangrove ecosystem, reporter strains in combination with non-cultivable approaches targeting AHL genes warrant further investigation (Viswanath et al., 2015). Another question worth pursuing in the future is the exploration of the parallel existence of AHL-producers and AHL-degraders in the rhizosphere environment and their roles in matter cycling $(\mathrm{C}, \mathrm{N}$, and $\mathrm{P})$ in mangrove plants.

\section{CONCLUSION}

This study confirms the existence of multiple AHL producers in the $K$. obovata rhizosphere environment, which provided novel information concerning the profiles of AHL signals in mangroveassociated bacteria. It is helpful for us to better understand the complex relationship between mangrove plants and microbes from chemical ecological perspective. Our work also speculated that mangrove rhizosphere bacteria might act as a candidate reservoir for identification new AHL-producers. In future, an urgent requisite aspect is to arbitrate the crucial role of AHLs associated traits of the rhizosphere bacteria, particularly their impact via signal mechanism on mangrove ecosystem, which are currently under way in our laboratory.

\section{AUTHOR CONTRIBUTIONS}

ZM and YL performed the experiment and write the manuscript. GL and HJ deal with the samples and analyzed the data. JZ and $\mathrm{ZC}$ provided funding and experimental conditions, and edited the manuscript.

\section{FUNDING}

This work was supported by National Natural Science Foundation of China (41476092), and S\&T Projects of Shenzhen Science and Technology Innovation Committee 
(JCYJ20150529164918736, KQJSCX2016022619041970, JCYJ 20150831192329178, and CXZZ20150529165045063), as well as the Marine Fishery Science and Technology \& Industry Development of Guangdong Province (A201603D05).

\section{ACKNOWLEDGMENT}

Special thanks to Jianxiang Feng and Mengqing Yin for assistance in samples preparation.

\section{REFERENCES}

Alfaro-Espinoza, G., and Ullrich, M. S. (2015). Bacterial N2-fixation in mangrove ecosystems: insights from a diazotroph-mangrove interaction. Front. Microbiol. 6:445. doi: 10.3389/fmicb.2015.00445

Alzubaidy, H., Essack, M., Malas, T. B., Bokhari, A., Motwalli, O., Kamanu, F. K., et al. (2016). Rhizosphere microbiome metagenomics of gray mangroves (Avicennia marina) in the Red Sea. Gene 576(2 Pt 1), 626-636. doi: 10.1016/j. gene.2015.10.032

Andreote, F. D., Jiménez, D. J., Chaves, D., Dias, A. C. F., Luvizotto, D. M., DiniAndreote, F., et al. (2012). The microbiome of Brazilian mangrove sediments as revealed by metagenomics. PLoS ONE 7:e38600. doi: 10.1371/journal.pone. 0038600

Atkinson, S., and Williams, P. (2009). Quorum sensing and social networking in the microbial world. J. R. Soc. Interface 6, 959-978. doi: 10.1098/rsif.2009.0203

Banerjee, G., and Ray, A. K. (2016). The talking language in some major Gramnegative bacteria. Arch. Microbiol. 147, 2379-2387. doi: 10.1007/s00203-0161220-x

Basak, P., Majumder, N. S., Nag, S., Bhattacharyya, A., Roy, D., Chakraborty, A., et al. (2015). Spatiotemporal analysis of bacterial diversity in sediments of Sundarbans using parallel 16S rRNA gene tag sequencing. Microb. Ecol. 69:500511. doi: 10.1007/s00248-014-0498-y

Berendsen, R. L., Pieterse, C. M., and Bakker, P. A. (2012). The rhizosphere microbiome and plant health. Trends Plant Sci. 17, 478-486. doi: 10.1016/j. tplants.2012.04.001

Biswa, P., and Doble, M. (2013). Production of acylated homoserine lactone by Gram positive bacteria isolated from marine water. FEMS Microbiol. Lett. 343, 34-41. doi: 10.1111/1574-6968.12123

Boyen, F., Eeckhaut, V., Van, I. F., Pasmans, F., Ducatelle, R., and Haesebrouck, F. (2009). Quorum sensing in veterinary pathogens: mechanisms, clinical importance, and future perspectives. Vet. Microbiol. 135, 187-195. doi: 10.1016/ j.vetmic.2008.12.025

Bulgarelli, D., Schlaeppi, K., Spaepen, S., van Themaat, E., and SchulzeLefert, P. (2013). Structure and functions of the bacterial microbiota of plants. Annu. Rev. Plant Biol. 64, 807-838. doi: 10.1146/annurev-arplant-050312120106

Cabrera, G., Perez, R., Gomez, J. M., Abalos, A., and Cantero, D. (2006). Toxic effects of dissolved heavy metals on Desulfovibrio vulgaris and Desulfovibrio sp. strains. J. Hazard. Mater. 135, 40-46. doi: 10.1016/j.jhazmat.2005.11.058

Certner, R. H., and Vollmer, S. V. (2015). Evidence for autoinduction and quorum sensing in white band disease-causing microbes on Acropora cervicornis. Sci. Rep. 5:11134. doi: 10.1038/srep11134

Chakraborty, A., Bera, A., Mukherjee, A., Basak, P., Khan, I., Mondal, A., et al. (2015). Changing bacterial profile of Sundarbans, the world heritage mangrove: impact of anthropogenic interventions. World J. Microbiol. Biotechnol. 31, 593-610. doi: 10.1007/s11274-015-1814-5

Chan, K. G., Atkinson, S., Mathee, K., Sam, C. K., Chhabra, S. R., Cámara, M., et al. (2011). Characterization of $\mathrm{N}$-acylhomoserine lactone-degrading bacteria associated with the Zingiber officinale rhizosphere: co-existence of quorum quenching and quorum sensing in Acinetobacter and Burkholderia. BMC Microbiol. 11:51. doi: 10.1186/1471-2180-11-51

Chen, Q., Zhao, Q., Li, J., Jian, S., and Ren, H. (2016). Mangrove succession enriches the sediment microbial community in South China. Sci. Rep. 6:27468. doi: $10.1038 /$ srep 27468

\section{SUPPLEMENTARY MATERIAL}

The Supplementary Material for this article can be found online at: http://journal.frontiersin.org/article/10.3389/fmicb. 2016.01957/full\#supplementary-material

FIGURE S1 | Taxonomic composition of the root-associated microbiome of $K$. obovata from rhizosphere soil samples based on 16S rRNA

sequencing. (A) Bacteria diversity at phylum level; (B) classes of Proteobacteria; and (C) the bacteria biodiversity at order level. The sequencing experiments were repeated three times.

Chevrot, R., Rosen, R., Haudecoeur, E., Cirou, A., Shelp, B. J., Ron, E., et al. (2006). GABA controls the level of quorum-sensing signal in Agrobacterium tumefaciens. Proc. Natl. Acad. Sci. U.S.A. 103, 7460-7464. doi: 10.1073/pnas. 0600313103

Chong, T. M., Koh, C. L., Sam, C. K., Choo, Y. M., Yin, W. F., and Chan, K. G. (2012). Characterization of quorum sensing and quorum quenching soil bacteria isolated from Malaysian tropical montane forest. Sensors (Basel) 12, 4846-4859. doi: 10.3390/s120404846

Chu, W. H., Vattem, D. A., Maitin, V., Barnes, M. B., and McLean, R. J. C. (2011). "Bioassays of quorum sensing compounds using Agrobacterium tumefaciens and Chromobacterium violaceum," in Quorum Sensing: Methods and Protocols. Methods in Molecular Biology, Vol. 692, ed. K. P. Rumbaugh (New York, NY: Springer Science+Business Media).

Cirou, A., Diallo, S., Kurt, C., Latour, X., and Faure, D. (2007). Growth promotion of quorum-quenching bacteria in the rhizosphere of Solanum tuberosum. Environ. Microbiol. 9, 1511-1522. doi: 10.1111/j.1462-2920.2007.01270.x

Crevelin, E. J., Canova, S. P., Melo, I. S., Zucchi, T. D., da Silva, R. E., and Moraes, L. A. (2013). Isolation and characterization of phytotoxic compounds produced by Streptomyces sp. AMC 23 from red mangrove (Rhizophora mangle). Appl. Biochem. Biotechnol. 171, 1602-1616. doi: 10.1007/s12010-013-0418-5

D'Angelo-Picard, C., Faure, D., Penot, I., and Dessaux, Y. (2005). Diversity of $\mathrm{N}$-acyl homoserine lactone-producing and -degrading bacteria in soil and tobacco rhizosphere. Environ. Microbiol. 7, 1796-1808. doi: 10.1111/j.14622920.2005.00886.x

DeAngelis, K. M., Lindow, S. E., and Firestone, M. K. (2008). Bacterial quorum sensing and nitrogen cycling in rhizosphere soil. FEMS Microbiol. Ecol. 66, 197-207. doi: 10.1111/j.1574-6941.2008.00550.x

Dias, A. C. F., Andreote, F. D., Dini-Andreote, F., Lacava, P. T., Sá, A. L. B., Melo, I. S., et al. (2009). Diversity and biotechnological potential of culturable bacteria from Brazilian mangrove sediment. World J. Microb. Biot. 25, 305-311. doi: 10.1007/s11274-009-0013-7

Gomes, N. C., Cleary, D. F., Calado, R., and Costa, R. (2011). Mangrove bacterial richness. Commun. Integr. Biol. 4, 419-423. doi: 10.4161/cib.4.4.15253

Gray, K. M., and Garey, J. R. (2001). The evolution of bacterial LuxI and LuxR quorum sensing regulators. Microbiology 147, 2379-2387. doi: 10.1099/ 00221287-147-8-2379

Haudecoeur, E., and Faure, D. A. (2010). fine control of quorum-sensing communication in Agrobacterium tumefaciens. Commun. Integr. Biol. 3, 84-88. doi: 10.4161/cib.3.2.10429

Hense, B. A., and Schuster, M. (2015). Core principles of bacterial autoinducer systems. Microbiol. Mol. Biol. Rev. 79, 153-169. doi: 10.1128/MMBR.00024-14

Hmelo, L., and Van Mooy, B. A. S. (2009). Kinetic constraints on acylated homoserine lactone-based quorum sensing in marine environments. Aquat. Microb. Ecol. 54, 127-133. doi: 10.3354/ame01261

Holguin, G., Vazquez, P., and Bashan, Y. (2001). The role of sediment microorganisms in the productivity, conservation and rehabilitation of mangrove ecosystems: an overview. Biol. Fertil. Soils 33, 265-278. doi: 10.1007/ s003740000319

Hong, Y., Liao, D., Hu, A., Wang, H., Chen, J., Khan, S., et al. (2015). Diversity of endophytic and rhizoplane bacterial communities associated with exotic Spartina alterniflora and native mangrove using Illumina amplicon sequencing. Can. J. Microbiol. 61, 723-733. doi: 10.1139/cjm-2015-0079

Huang, X., Gao, Y., Ma, Z., Lin, G. H., Cai, Z. H., and Zhou, J. (2016). Profile of Citrobacter freundii ST2, a multi-acyl-homoserine lactone producer associated 
with marine dinoflagellates. Curr. Microbiol. doi: 10.1007/s00284-016-1155-0 [Epub ahead of print].

Huang, Y., Zeng, Y., Yu, Z., and Zhang, J. (2013). Distribution and diversity of acyl homoserine lactone producing bacteria from four different soils. Curr. Microbiol. 66, 10-15. doi: 10.1007/s00284-012-0234-0

Jatt, A. N., Tang, K., Liu, J., Zhang, Z., and Zhang, X. H. (2015). Quorum sensing in marine snow and its possible influence on production of extracellular hydrolytic enzymes in marine snow bacterium Pantoea ananatis B9. FEMS Microbiol. Ecol. 91, 1-13. doi: 10.1093/femsec/fiu030

Jayaraman, D., Gilroy, S., and Ané, J. M. (2014). Staying in touch: mechanical signals in plant-microbe interactions. Curr. Opin. Plant Biol. 20, 104-109. doi: 10.1016/j.pbi.2014.05.003

Jia, H., Sun, X., Sun, H., Li, C., Wang, Y., Feng, X., et al. (2016). Intelligent microbial heat-regulating engine (IMHeRE) for improved thermo-robustness and efficiency of bioconversion. ACS Synth. Biol. 5, 312-320. doi: 10.1021/ acssynbio. 5 b00158

Joint, I., Tait, K., and Wheeler, G. (2007). Cross-kingdom signalling: exploitation of bacterial quorum sensing molecules by the green seaweed Ulva. Philos. Trans. R. Soc. Lond. B. Biol. Sci. 362, 1223-1233. doi: 10.1098/rstb.2007.2047

Joseph, C. M., and Phillips, D. A. (2003). Metabolites from soil bacteria affect plant water relations. Plant Physiol. Biochem. 41, 189-192. doi: 10.1016/S09819428(02)00021-9

Kaai, K., Kawana, Y., and Sasamoto, H. (2008). The relation between recalcitrancy of a mangrove plant, Kandelia obovata, and high endogenous level of abscisic acid. Plant Cell Tiss. Org. Cult. 94, 125-130. doi: 10.1007/s11240-008-9394-9

Krick, A., Kehraus, S., Eberl, L., Riedel, K., Anke, H., Kaesler, I., et al. (2007). A marine Mesorhizobium sp. produces structurally novel long-chain N-acylL-homoserine lactones. Appl. Environ. Microbiol. 73, 3587-3594. doi: 10.1128/ AEM.02344-06

Krumme, U., Herbeck, L. S., and Wang, T. (2012). Tide- and rainfall-induced variations of physical and chemical parameters in a mangrove-depleted estuary of East Hainan (South China Sea). Mar. Environ. Res. 82, 28-39. doi: 10.1016/j. marenvres.2012.09.002

Kuever, J., Rainey, F., and Widdel, F. (2005). "Desulfovibrio Kluyver and van Niel 1936, 397 AL," in Bergey's Manual ${ }^{\circledR}$ of Systematic Bacteriology, The Proteobacteria, Part C, The Alpha-, Beta-, Delta-, and Epsilonproteobacteria, Vol. 2, eds D. J. Brenner, N. R. Krieg, G. M. Garrity, J. T. Staley, D. R. Boone, P. D. Vos, et al. (New York, NY: Springer), 926-938.

Kumar, S., Tamura, K., and Nei, M. (2004). MEGA3: integrated software for molecular evolutionary genetics analysis and sequence alignment. Brief. Bioinform. 5, 150-163. doi: 10.1093/bib/5.2.150

Lamers, L. P., van Diggelen, J. M., den Camp, H. J., Visser, E. J., Lucassen, E. C., Vile, M. A., et al. (2012). Microbial transformations of nitrogen, sulfur, and iron dictate vegetation composition in wetlands: a review. Front. Microbiol. 3:156. doi: $10.3389 /$ fmicb. 2012.00156

Lane, D. J. (1991). "16S/23S rRNA sequencing," in Nucleic Acid Techniques in Bacterial Systematics, eds M. Goodfellow and E. Stackebrandt (New York, NY: John Wiley and Sons), 115-175.

Lang, J., Gonzalez-Mula, A., Taconnat, L., Clement, G., and Faure, D. (2016). The plant GABA signaling downregulates horizontal transfer of the Agrobacterium tumefaciens virulence plasmid. New Phytol. 210, 974-983. doi: 10.1111/nph. 13813

Leloup, J., Quillet, L., Berthe, T., and Petit, F. (2006). Diversity of the dsrAB (dissimilatory sulfite reductase) gene sequences retrieved from two contrasting mudflats of the Seine estuary, France. FEMS Microbiol. Ecol. 55, 230-238. doi: 10.1111/j.1574-6941.2005.00021.x

Liang, J., Chen, Y., Lan, C., Tam, N. F. Y., Zan, Q., and Huang, L. (2007). Recovery of novel bacterial diversity from mangrove sediment. Mar. Biol. 150, 739-747. doi: 10.1007/s00227-006-0377-2

Lv, H., Zhou, J., and Cai, Z. H. (2016). Dynamic variation of quorum sensing bacteria in a Scrippsiella trochoidea bloom. Ecol. Sci. 35, 23-30.

Ma, F., Wu, J., Wang, L., Yang, J., Li, S., Li, Z., et al. (2014). Characterization of the microbial community in the rhizosphere of Phragmites australis (cav.) trin ex. steudel growing in the Sun Island Wetland. Water Environ. Res. 86, 258-268. doi: 10.2175/106143013X13807328849297

Manefield, M., de Nys, R., Kumar, N., Read, R., Givskov, M., Steinberg, P., et al. (1999). Evidence that halogenated furanones from Delisea pulchra inhibit acylated homoserine lactone (AHL)-mediated gene expression by displacing the AHL signal from its receptor protein. Microbiology 145(Pt 2), 283-291. doi: 10.1099/13500872-145-2-283

Manefield, M., and Turner, S. L. (2002). Quorum sensing in context: out of molecular biology and into microbial ecology. Microbiology 148, 3762-3764. doi: 10.1099/00221287-148-12-3762

Marcial, G. N. C., Borges, L. R., Paranhos, R., Pinto, F. N., Mendonça, H. L., and Smalla, K. K. (2008). Exploring the diversity of bacterial communities in sediments of urban mangrove forests. FEMS Microbiol. Ecol. 66, 96-109. doi: 10.1111/j.1574-6941.2008.00519.x

Miralles, G., Grossi, V., Acquaviva, M., Duran, R., Claude Bertrand, J., and Cuny, P. (2007). Alkane biodegradation and dynamics of phylogenetic subgroups of sulfate-reducing bacteria in an anoxic coastal marine sediment artificially contaminated with oil. Chemosphere 68, 1327-1334. doi: 10.1016/j. chemosphere.2007.01.033

Ortiz-Castro, R., Contreras-Cornejo, H. A., Macias-Rodriguez, L., MacíasRodríguez, L., and López-Bucio, J. (2009). The role of microbial signals in plant growth and development. Plant Signal. Behav. 4, 701-712. doi: 10.4161/psb.4.8. 9047

Ortori, C. A., Dubern, J. F., Chhabra, S. R., Cámara, M., Hardie, K., Williams, P., et al. (2011). Simultaneous quantitative profiling of N-acyl-L-homoserine lactone and 2-alkyl-4(1H)-quinolone families of quorum-sensing signalling molecules using LC-MS/MS. Anal. Bioanal. Chem. 399, 839-850. doi: 10.1007/ s00216-010-4341-0

Parte, A., Krieg, N. R., Ludwig, W., Whitman, W., Hedlund, B. P., Paster, B. J., et al. (eds) (2010). Bergey's Manual of Systematic Bacteriology. New York, NY: Springer publisher.

Pollumaa, L., Alamae, T., and Mae, A. (2012). Quorum sensing and expression of virulence in Pectobacteria. Sensors 12, 3327-3349. doi: 10.3390/s120303327

Prakash, S., Ramasubburayan, R., Iyapparaj, P., Ahila, N. K., Sri Ramkumar, V., Palavesam, A., et al. (2015). Influence of physicochemical and nutritional factors on bacterial diversity in mangrove sediments along the southwest coast of Tamilnadu, India. Environ. Monit. Assess. 187:562. doi: 10.1007/s10661-0154713-1

Rajput, A., Kaur, K., and Kumar, M. (2016). SigMol: repertoire of quorum sensing signalling molecules in prokaryotes. Nucleic Acids Res. 44, D634-D639. doi: $10.1093 / \mathrm{nar} / \mathrm{gkv1076}$

Ransome, E., Munn, C. B., Halliday, N., Cámara, M., and Tait, K. (2014). Diverse profiles of N-acyl-homoserine lactone molecules found in cnidarians. FEMS Microbiol. Ecol. 87, 315-329. doi: 10.1111/1574-6941.12226

Romero, M., Martin-Cuadrado, A. B., Roca-Rivada, A., Cabello, A. M., and Otero, A. (2011). Quorum quenching in cultivable bacteria from dense marine coastal microbial communities. FEMS Microbiol. Ecol. 75, 205-217. doi: 10. 1111/j.1574-6941.2010.01011.x

Rout, M. E., and Southworth, D. (2013). The root microbiome influences scales from molecules to ecosystems: the unseen majority. Am. J. Bot. 100, 1689-1691. doi: 10.3732/ajb.1300291

Scharf, B. E., Hynes, M. F., and Alexandre, G. M. (2016). Chemotaxis signaling systems in model beneficial plant-bacteria associations. Plant Mol. Biol. 90, 549-559. doi: 10.1007/s11103-016-0432-4

Schikora, A., Schenk, S. T., and Hartmann, A. (2016). Beneficial effects of bacteriaplant communication based on quorum sensing molecules of the $\mathrm{N}$-acyl homoserine lactone group. Plant Mol. Biol. 90, 605-612. doi: 10.1007/s11103016-0457-8

Schloss, P. D., Westcott, S. L., Ryabin, T., Hall, J. R., Hartmann, M., Hollister, E. B., et al. (2009). Introducing mothur: open-source, platform-independent, community-supported software for describing and comparing microbial communities. Appl. Environ. Microbiol. 75, 7537-7541. doi: 10.1128/AEM. 01541-09

Schwartz, E. R., Poulin, R. X., Mojib, N., and Kubanek, J. (2016). Chemical ecology of marine plankton. Nat. Prod. Rep. 33, 843-860. doi: 10.1039/c6np00015k

Scott, R. A., Weil, J., Le, P. T., Williams, P., Fray, R. G., von Bodman, S. B., et al. (2006). Long- and short-chain plant-produced bacterial N-acyl-homoserine lactones become components of phyllosphere, rhizosphere, and soil. Mol. Plant Microbe. Interact. 19, 227-239. doi: 10.1094/MPMI-19-0227

Shaw, P. D., Ping, G., Daly, S. L., Cha, C., Cronan, J. E. Jr., Rinehart, K. L., et al. (1997). Detecting and characterizing N-acyl-homoserine lactone signal molecules by thin-layer chromatography. Proc. Natl. Acad. Sci. U.S.A. 94, 6036-6041. doi: 10.1073/pnas.94.12.6036 
Singh, R. P., and Reddy, C. R. (2014). Seaweed-microbial interactions: key functions of seaweed-associated bacteria. FEMS Microbiol. Ecol. 88, 213-230. doi: 10.1111/1574-6941.12297

Stackebrandt, E., and Goebel, B. M. (1994). Taxonomic note: a place for DNA-DNA reassociation and 16S rRNA sequence analysis in the present species definition in bacteriology. Int. J. Syst. Bacteriol. 44, 846-849. doi: 10.1099/00207713-444-846

Steidle, A., Sigl, K., Schuhegger, R., Ihring, A., Schmid, M., Gantner, S., et al. (2001). Visualization of $\mathrm{N}$-acylhomoserine lactone-mediated cell-cell communication between bacteria colonizing the tomato rhizosphere. Appl. Environ. Microbiol. 67, 5761-5770. doi: 10.1128/AEM.67.12.5761-5770.2001

Tait, K., Williamson, H., Atkinson, S., Williams, P., Cámara, M., and Joint, I. (2009). Turnover of quorum sensing signal molecules modulates cross-kingdom signalling. Environ. Microbiol. 11, 1792-1802. doi: 10.1111/j.1462-2920.2009. 01904.x

Tan, C. H., Koh, K. S., Xie, C., Tay, M., Zhou, Y., Williams, R., et al. (2014). The role of quorum sensing signalling in EPS production and the assembly of a sludge community into aerobic granules. ISME J. 8, 1186-1197. doi: 10.1038/ ismej.2013.240

Tan, C. H., Koh, K. S., Xie, C., Zhang, J., Tan, X. H., Lee, G. P., et al. (2015). Community quorum sensing signalling and quenching: microbial granular biofilm assembly. npj Biofilms Microbio. 1: 15006. doi: 10.1038/npjbiofilms. 2015.6

Taylor, M. W., Schupp, P. J., Baillie, H. J., Charlton, T. S., de Nys, R., Kjelleberg, S., et al. (2004). Evidence for acyl homoserine lactone signal production in bacteria associated with marine sponges. Appl. Environ. Microbiol. 70, 4387-4389. doi: 10.1128/AEM.70.7.4387-4389.2004

van Dam, N. M., and Bouwmeester, H. J. (2016). Metabolomics in the rhizosphere: tapping into belowground chemical communication. Trends Plant Sci. 21, 256-265. doi: 10.1016/j.tplants.2016.01.008

Varon-Lopez, M., Dias, A. C., Fasanella, C. C., Durrer, A., Melo, I. S., Kuramae, E. E., et al. (2014). Sulphur-oxidizing and sulphate-reducing communities in Brazilian mangrove sediments. Environ. Microbiol. 16, 845-855. doi: 10.1111/ 1462-2920.12237

Venturi, V., and Keel, C. (2016). Signaling in the rhizosphere. Trends Plant Sci. 21, 187-198. doi: 10.1016/j.tplants.2016.01.005

Viswanath, G., Jegan, S., Baskaran, V., Kathiravan, R., and Prabavathy, V. R. (2015). Diversity and N-acyl-homoserine lactone production by Gammaproteobacteria associated with Avicennia marina rhizosphere of South Indian mangroves. Syst. Appl. Microbiol. 38, 340-345. doi: 10.1016/j.syapm.2015.03.008

Wagner-Dobler, I., Thiel, V., Eberl, L., Bodor, A., Meyer, S., Ebner, S., et al. (2005). Discovery of complex mixtures of novel long-chain quorum sensing signals in free-living and host-associated marine alphaproteobacteria. Chembiochem. 6, 2195-2206. doi: 10.1002/cbic.200500189

Winans, S. C. (2006). Bacterial evolution by intelligent design. ACS Chem. Biol. 1, 429-431. doi: 10.1021/cb6003417
Yang, Q., Lei, A. P., Li, F. L., Liu, L. N., Zan, Q. J., Shin, P. K., et al. (2014). Structure and function of soil microbial community in artificially planted Sonneratia apetala and S. caseolaris forests at different stand ages in Shenzhen Bay, China. Mar. Pollut. Bull. 85, 754-763. doi: 10.1016/j.marpolbul.2014.02.024

Yin, M. Q., Feng, J. X., Huang, X. F., Cai, Z. H., Lin, G. H., and Zhou, J. (2016). Soil microbial community structure in natural and transplanted mangrove (Kandelia obovata) forests. Ecol. Sci. (in Chinese with English abstract) 6, 35-42.

Zeng, Y., Yu, Z., and Huang, Y. (2014). Combination of culture-dependent and independent methods reveals diverse acyl homoserine lactone-producers from rhizosphere of wetland plants. Curr. Microbiol. 68, 587-593. doi: 10.1007/ s00284-013-0513-4

Zhang, H. B., Wang, C., and Zhang, L. H. (2004). The quormone degradation system of Agrobacterium tumefaciens is regulated by starvation signal and stress alarmone (p)ppGpp. Mol. Microbiol. 52, 1389-1401. doi: 10.1111/j.1365-2958. 2004.04061.x

Zhang, S., Liao, S., Yu, X., Lu, H. W., Xian, J. A., Guo, H., et al. (2015). Microbial diversity of mangrove sediment in Shenzhen Bay and gene cloning, characterization of an isolated phytase-producing strain of SPC09 B. cereus. Appl. Microbiol. Biotechnol. 99, 5339-5350. doi: 10.1007/s00253-0156405-8

Zhang, X., Cang, Y. M., Qiang, X. G., Liang, C. X., and Lang, X. Q. (2016). Analysis of microbial community structure in mangrove constructed wetlandmariculture coupling system. Acta Hydrobiol. Sin. 40, 557-564.

Zhou, J., Lyu, Y. H., Richlen, M. L., Anderson, D. M., and Cai, Z. H. (2016). Quorum sensing is a language of chemical signals and plays an ecological role in algal-bacterial interactions. Crit. Rev. Plant Sci. 35, 81-105. doi: 10.1080/ 07352689.2016.1172461

Zhu, H., Thuruthyil, S. J., and Willcox, M. D. (2001). Production of N-acyl homoserine lactones by gram-negative bacteria isolated from contact lens wearers. Clin. Exp. Ophthalmol. 29, 150-152. doi: 10.1046/j.1442-9071.2001. 00397.x

Zimmer, B. L., May, A. L., Bhedi, C. D., Dearth, S. P., Prevatte, C. W., Pratte, Z., et al. (2014). Quorum sensing signal production and microbial interactions in a polymicrobial disease of corals and the coral surface mucopolysaccharide layer. PLoS ONE 9:e108541. doi: 10.1371/journal.pone.0108541

Conflict of Interest Statement: The authors declare that the research was conducted in the absence of any commercial or financial relationships that could be construed as a potential conflict of interest.

Copyright (c) $2016 \mathrm{Ma}, \mathrm{Lao}$, Jin, Lin, Cai and Zhou. This is an open-access article distributed under the terms of the Creative Commons Attribution License (CC BY). The use, distribution or reproduction in other forums is permitted, provided the original author(s) or licensor are credited and that the original publication in this journal is cited, in accordance with accepted academic practice. No use, distribution or reproduction is permitted which does not comply with these terms. 